\title{
Neonatal imaging
}

S K Misser, ${ }^{1}$ MB ChB, FC Rad (D) SA; T A Mitha, ${ }^{2}$ BSc, MB ChB, FCP (SA) Paed;

A S Shaik, ${ }^{3}$ MB ChB, FCS (SA), Cert (Paed Surg) SA

${ }^{1}$ Lake Smit and Partners, Durban, South Africa

${ }^{2}$ Specialist Paediatrician, Parklands Hospital, Durban, South Africa

${ }^{3}$ Paediatric Surgeon, Parklands Hospital, Durban, South Africa

Corresponding author: S K Misser (misser@lakesmit.co.za)

A neonatal first set of radiographs of a baby girl appear below. Describe the relevant findings and formulate the most appropriate clinical diagnosis. Please submit your response to misser@lakesmit.co.za not later than 23 September 2013. The winning respondent will receive a R1 000 award from the RSSA. A detailed diagnosis and discussion will be presented in the next issue of the $S A J R$.

S Afr J Rad 2013;17(3):116. DOI:10.7196/SAJR.934

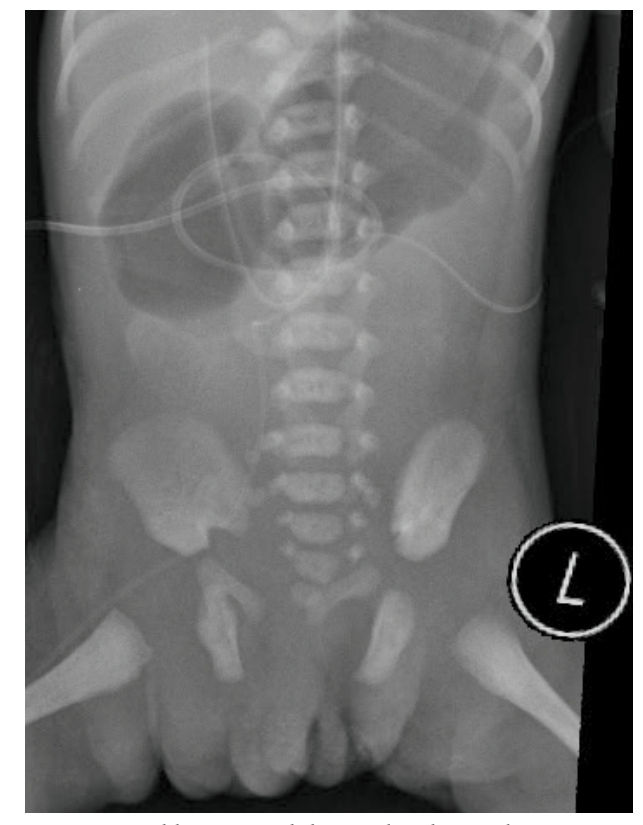

Fig. 1. Portable supine abdominal radiograph.

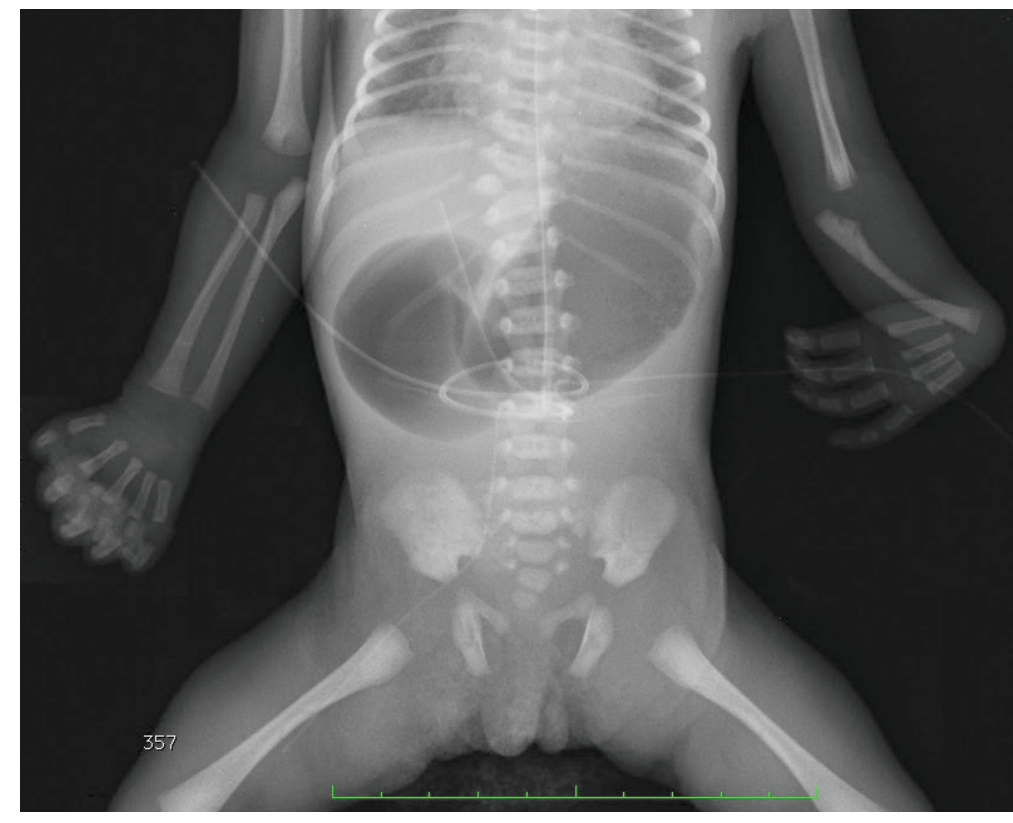

Fig. 3. Portable babygram radiograph.

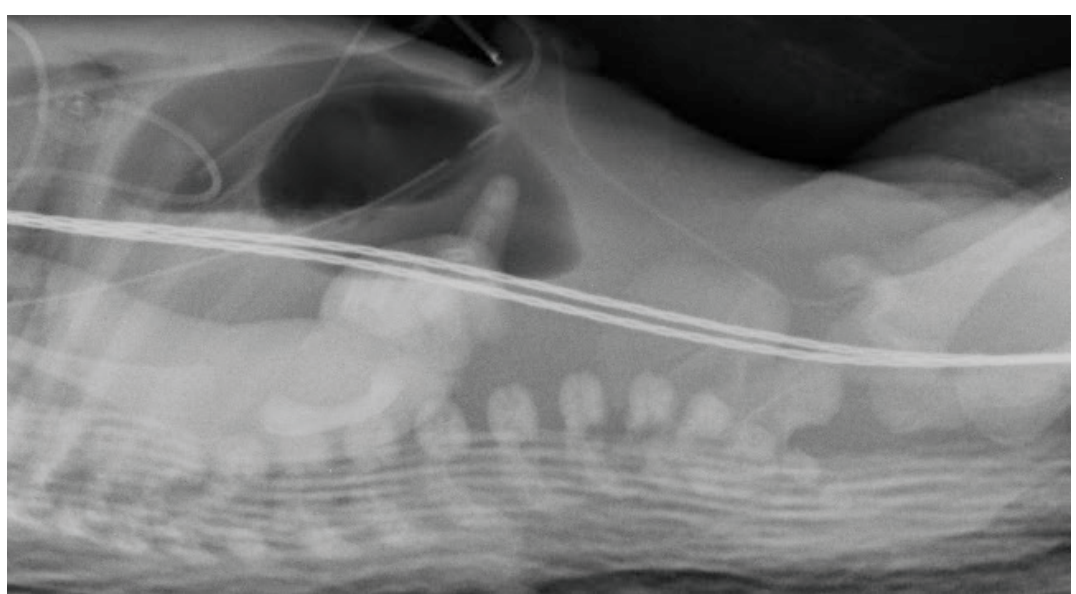

Fig. 2. Portable shoot-through lateral abdominal radiograph.

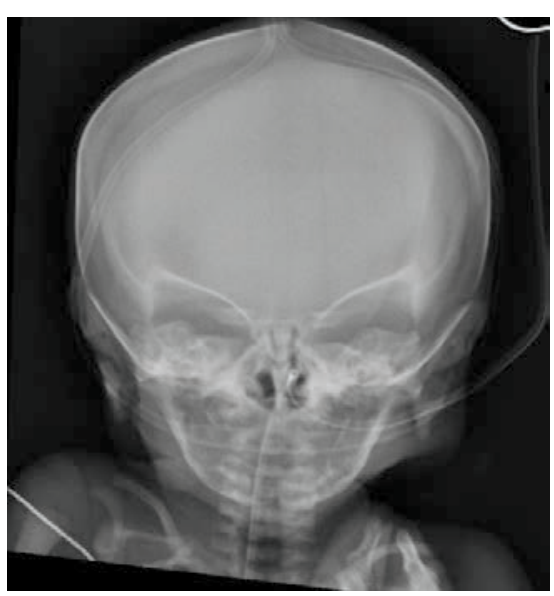

Fig. 4. Portable occipito-frontal radiograph. 